\title{
KETOGENIC DIET: EFFECTS ON GROWTH
}

The effects of the ketogenic diet on growth of 237 children (130 males, 107 females) treated for intractable epilepsy has been evaluated in a prospective cohort study (average follow-up 308 days) at the Johns Hopkins Hospital, Baltimore, MD. The age range at starting the diet was 2 months to 9 years 10 months (mean 3 years 8 months). At 1 and 2 years follow-up, 133 and 76 children were still on the diet, respectively; 102 (43\%) had discontinued the diet by 1 year. The diet was ineffective in 42 and too restrictive in 21 . Seizures were completely controlled in $34(25 \%)$ at 1 year; $>90 \%$ reduction in $37(27 \%)$; $50-90 \%$ seizure reduction in $44(33 \%)$; and $<50 \%$ reduction in $20(15 \%)$. Heights and weights were converted to $\mathrm{z}$ scores for age, representing the standard deviation from the mean. A child at average height for age and sex has a $\mathrm{z}$ score of 0 , and a child at the 97.5 th centile, a score of +2 (2SD above the mean). A rapid drop in weight $\mathrm{z}$ scores occurred in the first 3 months in all groups treated $(\mathrm{p}<0.01)$. In children starting the diet below the median weight, z scores remained constant after the initial loss, whereas those above the median at onset continued to show decreases in weight. Height $\mathrm{z}$ scores showed only small decreases in the first 6 months $(\mathrm{p}<0.5)$ but larger decreases by 2 year $(\mathrm{p}<0.01)$. These changes were independent of the sex, but very young children grew poorly ( $>2$ SD below the mean in height at 3 years) while on the diet and required careful follow-up. Non-communicative, especially and non-ambulatory, neurologically impaired children showed a greater decline in weight $\mathrm{z}$ scores than communicative and ambulatory patients, whereas changes in height were not related to neurologic status. (Vining EPG, Pyzik P, McGrogan J et al. Growth of children on the ketogenic diet. Dev Med Child Neurol December 2002;44:796-802). (Respond: EPG Vining MD, Meyer 2-147, JHH, $600 \mathrm{~N}$ Wolfe Street, Baltimore, MD 212897).

COMMENT. The study did not address the relation between growth/nutrition and the degree of ketosis. On a 4:1 ratio of fat/carbohydrate, as typically used in the Hopkins diet, the adverse effects on growth and weight reported, especially in younger children, may well be greater than that experienced with the more conservative Mayo Clinic ketogenic diet regimen. (see Millichap JG. Progress in Pediatric Neurology I, PNB Publishers, 1991;pp84-88; Ped Neur Briefs Nov 2001;15:86). Generally, the ketogenic diet should be expected to maintain normal growth and nutrition. In small children, the risk of adverse effects on growth are greater, and a ketogenic diet therapy for epilepsy requires careful monitoring.

Kidney stones, carbonic anhydrase inhibitors, and the ketogenic diet. The combined use of carbonic anhydrase inhibitors (topiramate [TPM] or zonisamide [ZNS]) and the ketogenic diet did not increase the risk of kidney stones compared to the ketogenic diet alone, in a study at The Johns Hopkins Medical Institutions, Baltimore, MD (Kossof EH, Pyzik PL, Furth SL et al. Epilepsia Oct 2002;43:1168-1171). Stones developed in 15 (6.7\%) of 221 children on the ketogenic diet alone, and in $5(6.3 \%)$ of 80 children treated with the diet in combination with a carbonic anhydrase inhibitor. The incidence of renal calculi when treatment includes the ketogenic diet is greater than that reported for TPM (1.5\%) and ZNS (3-4\%) alone. Patients developing stones while on combined therapy were more likely to have a family or previous history of renal abnormalities. Patients on combined therapy should have increased hydration, and urine alkalinization is recommended for those with previous renal abnormalities, family history of kidney stones, or hematuria. Carbonic anhydrase inhibitors should be discontinued if stones develop. 